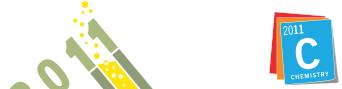

International Year of

\title{
SISTEMA DE REFRIGERAÇÃo CÍCLICO PARA UTILIZAÇÃO EM DESTILADOR TÉRMICO
}

\author{
Lucas Assirati*, Carlos A. Pereira e Luiz A. O. Nunes \\ Instituto de Física de São Carlos, Universidade de São Paulo, Av. Trabalhador São Carlense, 400, 13566-590 São Carlos - SP, Brasil
}

Recebido em 26/3/10; aceito em 26/7/10; publicado na web em 26/11/10

\begin{abstract}
CYCLIC COOLING SYSTEM FOR USE IN THERMAL DISTILLER. In this paper, we describe the design and construction of a low cost cyclic refrigeration system, for use in thermal distillers. The combination of cyclic refrigeration with a cooling condenser system allows reducing the waste of water found in ordinary distillation systems. The proposed system is simple, low-cost and can be built using standard components.
\end{abstract}

Keywords: refrigeration; distiller; cooling apparatus for distiller.

\section{INTRODUÇÃO}

A destilação é um processo físico presente no cotidiano da maioria dos laboratórios de pesquisa, ensino e em processos industriais. No processo de destilação fracionada, uma mistura é vaporizada através do aumento de sua temperatura; se os componentes desta mistura possuírem diferentes pontos de ebulição, podem ser coletados separadamente por um condensador. O condensador é envolvido por uma serpentina, na qual água circula e atua como fluido refrigerante. Ao entrar em contato com a superfície fria do condensador a substância evaporada retorna ao seu estado líquido, podendo ser coletada. Após a água ser utilizada como fluido refrigerante, em geral, é completamente descartada. Por exemplo, em um destilador que dissipe em seu sistema de aquecimento potência de $3000 \mathrm{~W}$ são descartados aproximadamente $20 \mathrm{~L}$ de água potável, para produzir em torno de $3 \mathrm{~L}$ de água destilada.

Atualmente há uma conscientização mundial no sentido de se conservar os recursos hídricos, evitando tais desperdícios. Tentando contribuir nesta direção, desenvolvemos um sistema de refrigeração de fácil construção, baixo custo e que reutiliza de maneira cíclica o fluido refrigerante do condensador de um destilador térmico. $\mathrm{O}$ sistema de refrigeração cíclico construído foi testado em condições reais e apresentou excelente desempenho, o que motivou a redação desta nota técnica.

\section{PRINCÍPIO DE FUNCIONAMENTO E DETALHES DE CONSTRUÇÃO}

O princípio de funcionamento do sistema de refrigeração baseiase na reutilização cíclica do fluido refrigerante (água, por exemplo). O fluido refrigerante é forçado a circular entre o condensador do destilador e o trocador de calor. O trocador de calor é responsável por remover o calor absorvido pelo fluido refrigerante e transferi-lo ao ambiente. Na Figura 1 é apresentado o desenho esquemático do princípio de funcionamento do refrigerador desenvolvido. A Figura 2 ilustra o desenho esquemático do protótipo construído.

\section{Principais componentes utilizados}

Bomba: no protótipo desenvolvido utilizamos uma eletrobomba de drenagem (conhecida comumente como bomba de tanquinho de

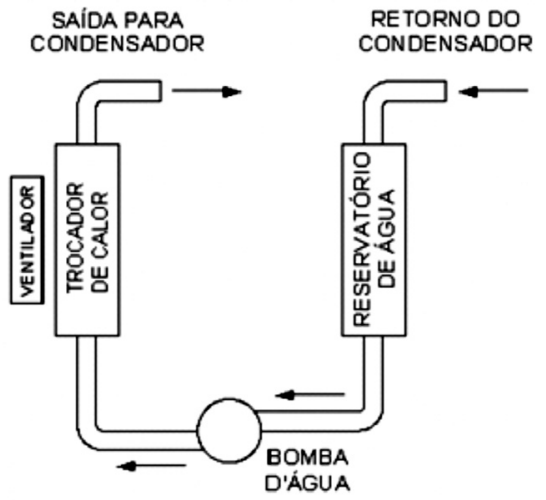

Figura 1. Desenho esquemático do princípio de funcionamento do sistema de refrigeração desenvolvido

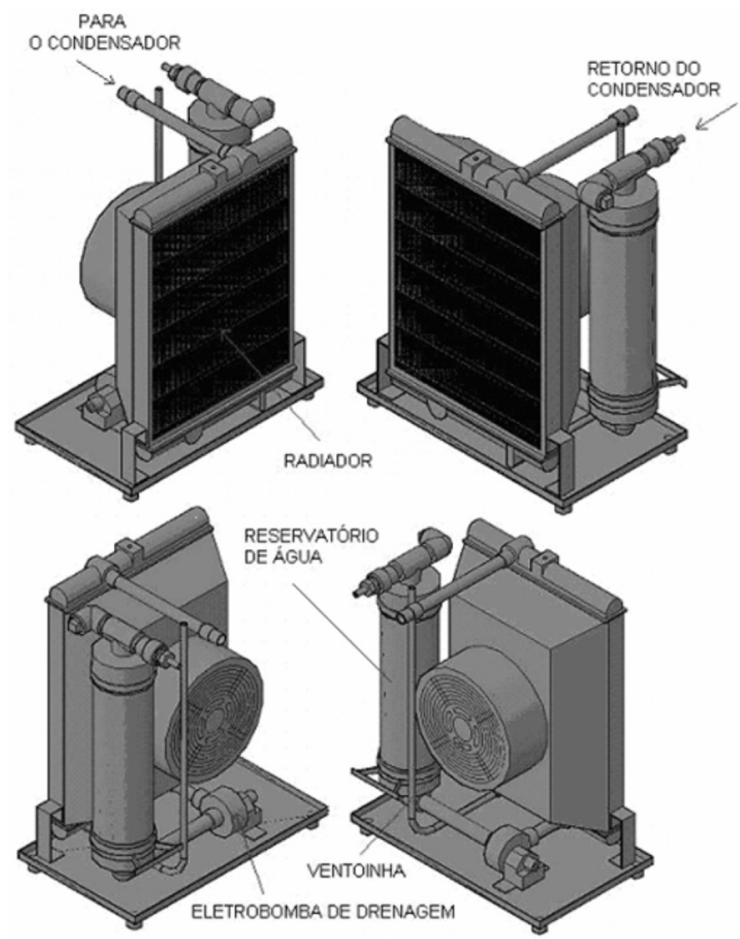

Figura 2. Desenho esquemático do protótipo construído 
lavar roupas) modelo-31EBD250041, fabricada pela Eberle Motores Elétricos. Ela tem por finalidade manter o fluxo do fluido refrigerante entre o condensador e o trocador de calor.

Trocador de calor: utilizamos um radiador automotivo, especificado para carros de até mil cilindradas. A finalidade dele é remover o calor do fluido refrigerante e transferi-lo para o ambiente.

Ventoinha: utilizamos uma ventoinha modelo RAX - 2, fabricada pela Venti Silva. Sua finalidade é aumentar o rendimento do trocador de calor, através do processo de ventilação forçada. No sistema desenvolvido, o conjunto trocador de calor mais sistema de refrigeração forçada é capaz de manter em perfeito funcionamento um destilador que dissipe potência elétrica de até $5000 \mathrm{~W}$.

Reservatório: o reservatório do fluido refrigerante foi construído com cano PVC de 4 polegadas e permite a fácil adição do fluido refrigerante, caso seja necessário.

Ressaltamos que, na construção do protótipo, não é necessário seguir à risca a listagem dos componentes aqui mencionados. Caso o leitor opte, poderá utilizar materiais como canos de cobre ou aço inox, ou combinar a utilização de duas ou mais ventoinhas menores, por exemplo. No entanto, tais adaptações devem respeitar a potência térmica máxima a ser dissipada pelo condensador. Caso tal limite não seja respeitado, existe risco de danificar o destilador ou deste não operar na sua faixa de rendimento ótimo. Na Figura 3 mostramos a fotografia do protótipo construído.

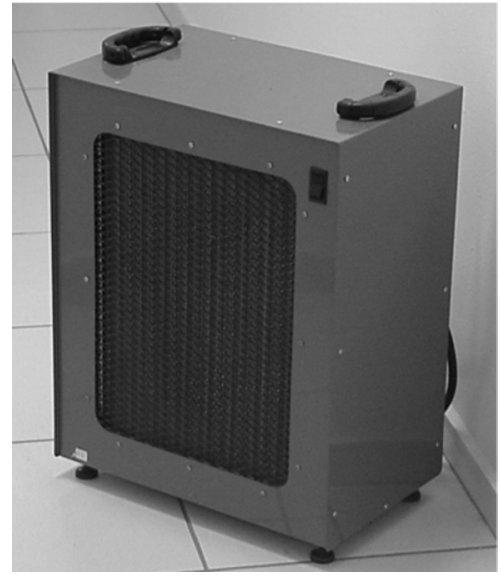

Figura 3. Fotografia do protótipo construído

\section{Análise da eficiência do sistema de refrigeração}

Com o objetivo de testar o sistema desenvolvido, utilizamos um destilador comercial que dissipa potência elétrica de $3000 \mathrm{~W}$ em seu sistema de aquecimento. Inicialmente levantamos sua característica de produção, que coincidiu com a especificada pelo fabricante, isto é, o destilador apresentou produção média de $53 \mathrm{~mL}$ de água destilada por minuto, consumindo na refrigeração de seu condensador cerca de 32,1 L em 1 h de operação. Nesta situação, a água descartada do sistema de refrigeração do condensador estava aproximadamente à $73{ }^{\circ} \mathrm{C}$.

A seguir, conectamos ao condensador do destilador comercial o sistema de refrigeração desenvolvido. Neste caso, obtivemos produção média de $42 \mathrm{~mL}$ de água destilada por minuto. Nesta situação, a temperatura do fluido refrigerante, agora mantido em um circuito fechado, estabilizou-se em $52{ }^{\circ} \mathrm{C}$ (após $25 \mathrm{~min}$ ). Num segundo momento, reduzimos a ventilação forçada sobre o radiador automotivo. Nesta situação, a produção média foi de $59 \mathrm{~mL}$ de água destilada por minuto e após $10 \mathrm{~min}$ a temperatura do fluido refrigerante estabilizouse em aproximadamente $75^{\circ} \mathrm{C}$. Na Figura 4 mostramos o gráfico da produção integrada de água destilada nas três situações analisadas.

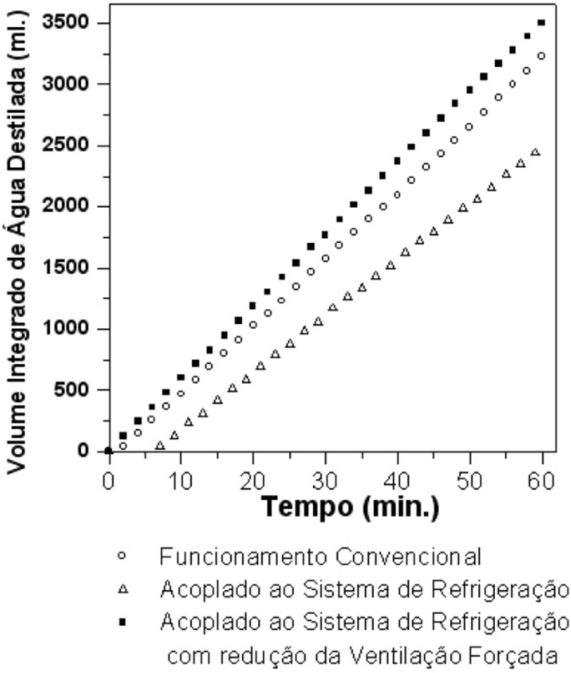

Figura 4. Produção integrada de água destilada

Na Figura 5 mostramos a evolução temporal da temperatura do fluido refrigerante nos casos acima citados.

Com a redução do fluxo da ventilação forçada sobre o trocador de calor, obtivemos produção média de água destilada similar à especificada pelo fabricante do destilador. Tal redução de ventilação foi necessária, pois no primeiro momento o fluido refrigerante estava removendo calor não só do condensador, mas de todo o corpo do destilador. O fluxo de ventilação forçado foi ajustado de modo a se obter uma produção similar à especificada pelo fabricante do destilador, podendo tal fluxo de ventilação ser controlado eletricamente (através do controle da tensão aplicada à ventoinha), mecanicamente (obstruindo-se o fluxo), ou através da utilização de uma ventoinha de menor potência. Na situação descrita nesta nota obstruímos o fluxo mecanicamente.

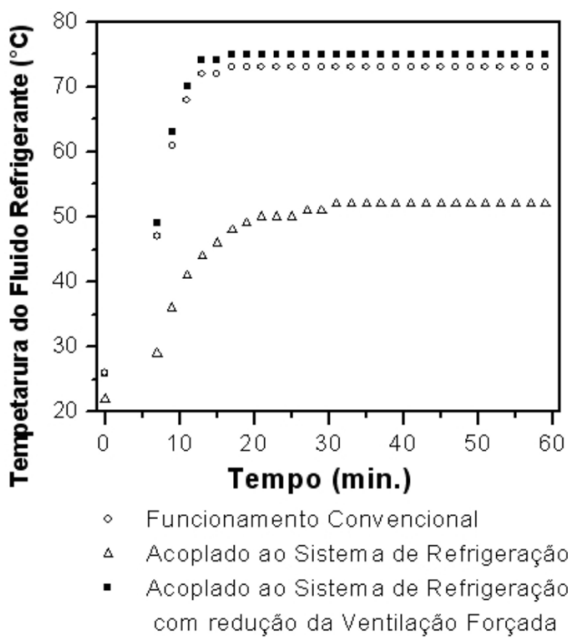

Figura 5. Evolução temporal da temperatura do fluido refrigerante

\section{CONCLUSÃO}

A montagem do sistema de refrigeração cíclico requer somente peças de baixo custo e de fácil obtenção. A sua montagem é simples, não necessitando de mão-de-obra especializada. As expectativas quanto à eliminação do descarte de água, tanto quanto à durabilidade do sistema e à produção de água destilada, foram plenamente atendidas. 